\title{
La sensibilidad lingüística de Lorenzo Campano en su producción científico-técnica
}

\author{
Mario Salvatore Corveddu
}

Corveddu, M. S. (2021). La sensibilidad lingüística de Lorenzo Campano en su producción científicotécnica. Revista de Filología y Lingüística de la Universidad de Costa Rica, 47(2), e46943.

doi: https://doi.org/10.15517/rfl.v47i2.46943

\section{(9) $\mathbb{P Q \Theta}$}

Doi: https://doi.org/10.15517/rfl.v47i2.46943

URL: https://revistas.ucr.ac.cr/index.php/filyling/index 
Revista de Filología y Lingüística de la Universidad de Costa Rica

ISSN: 0377-628X

ISSN: 2215-2628

filyling@gmail.com

Universidad de Costa Rica

Costa Rica

\title{
La sensibilidad lingüística de Lorenzo Campano en su producción científico- técnica
}

\author{
Corveddu, Mario Salvatore \\ La sensibilidad lingüística de Lorenzo Campano en su producción científico-técnica \\ Revista de Filología y Lingüística de la Universidad de Costa Rica, vol. 47, núm. 2, e46943, 2021 \\ Universidad de Costa Rica, Costa Rica \\ Disponible en: http://www.redalyc.org/articulo.oa?id=33266553008 \\ DOI: https://doi.org/10.15517/rfl.v47i2.46943
}

\section{(c) $\underset{\mathrm{BY}}{(\mathrm{N}) \mathrm{NO}} \mathrm{No}$}

Esta obra está bajo una Licencia Creative Commons Atribución-NoComercial-SinDerivar 3.0 Internacional. 


\title{
La sensibilidad lingüística de Lorenzo Campano en su producción científico-técnica
}

\author{
The Linguistic Sensitivity of Lorenzo Campano in His Scientific and Technical Production
}

Mario Salvatore Corveddu

Università Cattolica del Sacro Cuore, Milán, Italia

mariosalvatore.corveddu@unicatt.it

iD https://orcid.org/0000-0002-6667-1523

\author{
DOI: https://doi.org/10.15517/rfl.v47i2.46943 \\ Redalyc: http://www.redalyc.org/articulo.oa?id=33266553008
}

Recepción: 03 Junio 2020

Aprobación: 02 Julio 2020

\section{RESUMEN:}

El presente estudio se centra en la figura de Lorenzo Campano, autor prolífico del siglo XIX del que nada conocemos fuera de su obra compuesta por libros de diverso tipo entre los cuales destacan obras pedagógicas, cuentos, manuales científicos-técnicos y además un diccionario. Nos centraremos en su obra de carácter especializado, un manual sobre el curtido y adobo de la piel y otro sobre la producción de la cerveza, con el objetivo de analizar la concienciación lingüística del autor y su percepción de las dinámicas léxicas. A lo largo del estudio hemos analizado el paratexto y las anotaciones con las que Campano enriquece sus obras, y hemos encontrado huellas no solo de su sensibilidad al dato lingüístico, sino de su sensibilidad a los procesos de cambio léxico; estos últimos, debidos al desarrollo diatécnico del siglo XIX. La naturaleza y los contenidos de las anotaciones de Campano, por un lado, ponen en evidencia que su concienciación lingüística influenció su producción y, por otro lado, documentan algunos de los procesos de cambio sin precedentes que el léxico estaba experimentando.

Palabras Clave: historia del léxico, léxico técnico, lexicología, Lorenzo Campano, siglo XIX.

\section{ABSTRACT:}

The present study focuses on the figure of Lorenzo Campano, a prolific nineteenth-century author of whom we know nothing outside of his work composed of books of various kinds, among which stand out pedagogical works, stories, scientific-technical manuals, and a dictionary. We will focus on his specialized work, a manual on leather tanning and dressing and another on beer production, with the aim of analyzing the author's linguistic awareness and his perception of lexical dynamics. Throughout the study, we have analyzed the paratext and the annotations with which Campano enriches his works, and we found traces not only of his sensitivity to linguistic data, but of sensitivity to the processes of lexical change due to the diatechnic development of the nineteenth century. The nature and contents of Campano's annotations on the one hand make it clear that his linguistic awareness influenced his production, on the other hand they document some of the processes of the unprecedented change that the lexicon was undergoing.

KEYWORDS: history of lexicon, technical lexicon, lexicology, Lorenzo Campano, nineteenth century.

\section{INTRODUCCIÓN}

En la historia moderna de la lengua española, el siglo XIX es una etapa que solo desde hace unas pocas décadas ha despertado el interés de los historiadores de la lengua. La postura clásica, según la cual el desarrollo del español había terminado en el siglo XVIII ${ }^{1}$, no consideraba las dinámicas de un contexto sociocultural en el que el progreso científico-técnico daría origen a una reconfiguración de España, cuyos efectos permearon profundamente la dimensión lingüística. Los estudios que han investigado este arco temporal enfocándose en las diferentes ramas del conocimiento técnico y científico nos ofrecen una imagen suficientemente detallada de ambos siglos ${ }^{2}$. La importancia de analizar el léxico científico-técnico y sus fenómenos consiste en que presenta una dinámica propia y sus períodos evolutivos no tienen por qué coincidir con los de los géneros literarios o con los de otros fenómenos lingüísticos (Garriga Escribano, 2015, p. 62).

El siglo XVIII se presenta como el momento en el que se despierta el interés hacia el mundo de las ciencias y de las técnicas (que en este momento sería más preciso designar artes y oficios), empujado por el mismo deseo 
de progreso que ya habían experimentado otros países europeos. En este contexto, la lengua se convirtió en un instrumento fundamental para introducir aquellos conceptos necesarios para el desarrollo de España ${ }^{3}$. En el siglo XIX la implantación del ferrocarril, de la electricidad, de la fotografía, la telefonía y la telegrafía, da lugar a una enorme cantidad de neologismos. Ciencias como la química, la física, la matemática experimentan importantes avances y el léxico se asienta en el tejido léxico español por la divulgación de estas ciencias (Garriga Escribano, 2015, p. 63). Estas dinámicas terminaron enriqueciendo el panorama editorial de obras de divulgación, traducciones u originales, en el que es común encontrar incluso anotaciones de carácter lingüístico, recursos de suma importancia para esbozar una imagen de la lengua en aquella época.

El presente estudio propone el análisis de las reflexiones lingüísticas contenidas en las obras de Lorenzo Campano, autor del que nada sabemos fuera de su producción, compuesta por libros de diversos tipos, como lexicográfico, de carácter especializado, didáctico y alguno más de diferente naturaleza. En particular, nos enfocaremos en su producción científico-técnica, es decir, el Manual del cervecero y del fabricante de bebidas gaseosas y fermentadas (1869a) y Manual del curtidory del zurrador (1869b). El estudio se plantea el objetivo de ofrecer algunos detalles sobre Lorenzo Campano, en concreto, investigar su producción técnica para evaluar la influencia de su sensibilidad lingüística a través de las reflexiones que nacen de las anotaciones de nuestro autor. Además, el estudio nos permite reflexionar acerca de las dinámicas que, en este periodo de la historia de la lengua española, redefinen el léxico de sectores técnicos como la cervecería y el curtido de la piel.

\section{La PRoducción CIENTÍFico-TÉcnica de LoREnZo CaMPano}

Los estudios de la tipología que proponemos suelen abrirse con un paréntesis bibliográfico sobre el autor objeto de la investigación, por medio del cual contextualizar su obra y su estilo. Sin embargo, a la hora de abordar la figura de Lorenzo Campano, solo podemos contar con su obra, única heredad de este prolífico estudioso. El elemento que ha llamado nuestro interés es la heterogeneidad de su producción, la cual se compone de obras de valor didáctico ${ }^{4}$, de carácter especializado ${ }^{5}$ y de diferente naturaleza ${ }^{6}$, entre las cuales destaca su diccionario ${ }^{7}$. Nuestra hipótesis de partida es que su sensibilidad al dato lingüístico, confirmada por su repertorio lexicográfico ${ }^{8}$, pueda haber influenciado la redacción de sus manuales técnicos sobre la industria cervecera y el curtido y adobo de cueros. En este apartado presentamos los dos manuales que constituyen el corpus de nuestra investigación, y ofrecemos una contextualización de estas obras en el contexto editorial del tiempo.

\subsection{Manual del cervecero y del fabricante de bebidas gaseosas y fermentadas (1869)}

En 1869 Lorenzo Campano publica el Manual del cervecero y del fabricante de bebidas gaseosas y fermentadas, obra que enriquece un contexto donde los estudios dedicados a la industria cervecera escaseaban. El panorama editorial decimonónico estaba orientado hacia el aspecto técnico de la producción, tema que en muchas ocasiones compartía protagonismo con el vino, los licores y bebidas gaseosas, entre otras ${ }^{9}$. Es el siglo en el que se publica la primera obra de referencia sobre el tema en España a cargo de Juan Manuel Ballesteros (1827), quien subraya la falta de literatura previa donde se tratase el tema de forma exclusiva ${ }^{10}$. Poco tiempo después apareció la obra de José Ruiz Pérez Tratado teórico y práctico de la fermentación espirituosa o alcohólica (1845), título genérico que trasluce su naturaleza propiamente científica donde el tema de la cerveza se enmarca en la dimensión más amplia del análisis del proceso químico de transformación del mosto en alcohol. En 1848 Martínez publica su Manual para la fabricación de vinos y modo de remediar sus alteraciones, donde el proceso de producción de la cerveza se describe con un detalle mayor y por primera vez se proporciona una descripción de las materias primas idóneas en la producción de cerveza. En este contexto, el manual objeto 
de nuestro estudio, el cual cuenta con una extensión de 304 páginas, se puede considerar la obra técnica más completa sobre la cerveza escrita en España en el siglo XIX, donde se trata de forma exclusiva y sin combinar la cervecería con la producción de otras bebidas alcohólicas.

La obra se divide en dos partes, la primera y más importante dedicada a la cerveza y la segunda a la producción de las bebidas gaseosas; a estas se une un apéndice de cuatro páginas sobre la sidra. Sin renunciar a la tecnicidad que un tema relacionado tan estrictamente al mundo de la química requiere, la organización del discurso refleja una atención al aspecto pragmático, es decir, a la utilidad para el lector. Campano trata las materias primas necesarias para la producción de la cerveza ${ }^{11}$, a fin de dedicarse luego a la descripción del método de preparación de la malta y su trabajo ${ }^{12}$ para obtener el mosto que, una vez tratado con lúpulo, se somete al proceso de fermentación, al cual el autor dedica todo un capítulo (1869a, pp. 105-123). Campano enriquece el manual con la presentación de los “principales métodos empleados en los países principales en la producción de la bebida" 13 y con reflexiones acerca de algunos aspectos propios de los procesos de elaboración ${ }^{14}$. Por primera vez en la historia del discurso sobre la industria cervecera se explica el arte de manejar la cerveza en la bodega de conserva ${ }^{15}$, se ofrece una descripción detallada de los instrumentos necesarios ${ }^{16} \mathrm{y}$ los detalles de una fábrica con su bodega de almacenaje ${ }^{17}$.

La segunda parte del manual, dedicada a los métodos para fabricar bebidas gaseosas, presenta una extensión que se limita a las 46 páginas y una estructuración más sencilla con respecto a la primera parte dedicada al tema central de la obra. Son tres los asuntos de la sección: los métodos de gasificación del agua, la producción de bebidas gaseosas medicinales y estándares, además de las técnicas de producción de los jarabes.

\subsection{Manual del curtidor y del zurrador (1869)}

En el mismo año el autor publica el Manual del curtidor y del zurrador, obra dedicada a una de las manufacturas más antiguas del hombre (Thomson, 1981, p. 141) que, a pesar de su historicidad, cuenta con escasos recursos documentales ${ }^{18}$. La primera obra escrita publicada y que abre la tradición descriptiva del tema es Las Tenerias y adovo de cueros de Terreros y Pando (1754, XII, pp. 186-209), fragmento de la adaptación al español de Le Spectacle de la Nature, obra publicada en ocho tomos y nueve libros desde 1735 hasta 1750 por el abad Antoine Nöel Pluche. Aun siendo la traducción de un texto francés, en un periodo donde la traducción desempeña un papel central en el progreso sociocultural del país ${ }^{19}$, el esmero con el que el padre Terreros y Pando adapta la obra convierte este texto en uno de los recursos fundamentales sobre el método tradicional del curtido de la piel ${ }^{20}$. El primer manual pensado y diseñado en lengua española se publicará solo en 1805 a cargo de Cayetano Miguelez, Arte de Curtir ó Instruccion General de Curtidos dado á la luz por Don Cayetano Miguelez, vecino de esta corte, que, además de ofrecer una descripción completa del sector, proporciona un glosario en el que se definen los términos que según el autor son los más importantes para comprender la obra. El manual de Campano se localiza en un momento de fuerte dinamismo editorial, sin embargo, no son muchas las obras que se dedican por entero al curtido de la piel, tema que en muchos casos se incluía en manuales de química y se analizaba solo a partir de esta perspectiva; aún menos las que no sean una traducción de obras extranjeras.

El Manual del curtidor y del zurrador (1869b) presenta una estructuración de los contenidos que se conforma a los nuevos patrones que se individúan en obras de la misma época, donde el proceso de elaboración ya no se presenta como simple secuencias de actividades, sino como un conjunto heterogéneo de prácticas que se adaptan al producto que se quiere obtener. Campano organiza el manual en cuatros partes: la primera, en la que se introducen las nociones generales y las primeras preparaciones a las que se someten las pieles (pp. 11-53); la segunda, dedicada al proceso de curtido, diferenciándolo según las materias primas empleadas (pp. 69-166); la tercera, destinada al arte del zurrador, es decir, al conjunto de procesos 
de elaboración al que se someten los cueros curtidos para que adquieran las propiedades físicas y estéticas deseadas (pp. 167-223); la última sección consta de un diccionario de las sustancias vegetales empleadas durante toda la producción, además de una lista de 128 plantas para la extracción del tanino. A lo largo del manual, se aprecia el interés hacia las técnicas adoptadas del extranjero, en particular en Francia, cuya influencia se extenderá al nivel lingüístico y a las anotaciones que analizaremos en el siguiente apartado.

\section{ANÁlisis DEL PARATEXTo}

Las reflexiones lingüísticas con las que los autores valoraban las propias obras representan un recurso documental fundamental para la historia del español moderno. Esta exigencia ha sido percibida por diferentes autores, sobre todo los que se dedicaban a la traducción de obras extranjeras, quienes han manifestado una preocupación hacia el aspecto terminológico y han subrayado la necesidad de adaptar el léxico español. La química es el ámbito en donde este fenómeno se ha estudiado con mayor profundidad, puesto que su dinámica de evolución y el rol que la lengua desempeña en este sector han atraído los intereses de la mayoría de los investigadores ${ }^{21}$.

Ahora bien, nuestro estudio se orienta hacia las técnicas, área de la que disponemos de menos conocimientos, si bien las dinámicas extralingüísticas del tiempo afectaron la lengua de una forma que merece la pena profundizar. En este apartado, tras una presentación sencilla de los paratextos de las dos obras, analizaremos las reflexiones y anotaciones lingüísticas con la pretensión de reconstruir los motivos que llevaron a Campano a enriquecer sus manuales con explicaciones e informaciones accesorias. La metodología adoptada se basa esencialmente en la dimensión léxica; así, se investiga, por una parte, la lexicografía diacrónica ${ }^{22}$ y, por otra parte, la literatura del tiempo sobre los mismos asuntos ${ }^{23}$.

\subsection{El paratexto en el Manual del cervecero}

Con paratexto entendemos el nivel del texto constituido por el prólogo, las notas, los apéndices o los repertorios terminológicos; en general, admitimos la definición de Genette (1987, p. 7) según la que el paratexto es un momento durante el cual el texto se pone en relación libremente con el lector ${ }^{24}$. Su rol de herramienta complementaria ha sido investigado por Pinilla y Lepinette (2009), quienes subrayan su importancia en la actividad del traductor, el cual puede completar, precisar y contradecir el objeto de la traducción (Pinilla y Lepinette, 2009, p. 124).

Tratándose de obras originales, en los manuales objeto de nuestro estudio el paratexto mantendrá solo parcialmente esta función, pues se configura como un canal por medio del cual ofrecer al lector un caudal nocional ulterior respecto al texto de la obra. A través de este canal se vehiculan distintas tipologías de informaciones, desde las notas enciclopédicas sobre ciertas cuestiones necesarias para acceder a los contenidos, hasta las notas terminológicas, que son las que iremos analizando a lo largo de este apartado.

Por lo que se refiere al Manual del Cervecero, el paratexto consta de una introducción (1869a, pp. 5-7) y 20 notas, de las cuales ocho presentan un contenido metalingüístico (en adelante nota lingüística) y las demás interpretables como enciclopédicas. A continuación, se reproducen las notas con contenido lingüístico (las cursivas son del texto):

i. (nota lingüística a la palabra malt ó malta): Nombre con el cual se designa la preparación de la cebada con destino á la fabricación de la cerveza. En el curso de la obra haremos uso de ély de su derivado maltage (1869a, p. 21). ii. (nota lingüística a la palabra lupulina): Sustancia pulverulenta, resiniforme, dorada, aromática y amarga, que se encuentra

en la base y la superficie de las brácteas que forman las piñas del lúpulo á su madurez (1869a, p. 27). iii. (nota lingüística a la palabra cubeta oval): Los franceses la llaman "reverdoir"(1869a, p. 80). 
iv. (nota lingüística a raspadores especiales a papilla muy fina): Los raspadores ó rallos son como los usados en la fabricación del azúcar de remolachas (1869a, p. 157).

v. (nota lingüística a la palabra krousembier): Mosto que está en la primera fase de la fermentación (1869a, p. 164).

vi. Repite la nota 3.

vii. (nota lingüística con contenido etimológico): Era llamada "cerevisia ó cervisia”. Lo que hoy llamamos malt tenía el nombre de "brace" (brase), que bien pueden ser la raiz de cerveza y bracco que llevan la bebida y su manipulación (1869a, p. 245). viii. (nota lingüística a la palabra carbonato de cal): Blanco de España (1869a, p. 250).

Desde una primera lectura podemos notar que la mayoría de las notas sirven para definir una unidad léxica, en particular las 1, 2, 4, 5 y 8 . Las notas 3 y 6, en cambio, introducen un equivalente sinonímico en lengua francés y finalmente la número 7 es una nota enciclopédica en la que se presenta una reflexión etimológica. Las anotaciones en las que el autor proporciona la definición de un término manifiestan una profunda sensibilidad lingüística, además de un interés hacia la accesibilidad de la obra.

Cada una de estas notas encierra una motivación diferente, en la 1 se define la palabra malt, la cual en el texto va acompañada por el equivalente malta. La historia lexicográfica de este sustantivo nos ofrece algunos elementos útiles a la hora de reconstruir las razones detrás de esta nota. En general, se trata de una voz de la que no disponemos información completa, pues su origen etimológico es incierto. El Diccionario Crítico Etimológico Castellano e Hispano (en adelante DECH) asocia esta voz al inglés malt, sustantivo de origen germánico emparentado con melt 'derretir', que al entrar en el castellano se ha adaptado a la forma latina maltha 'especie de asfalto' o al nombre geográfico Malta (Corominas y Pascual, 1980, s.v. Malta). Otra posibilidad sería el francés malt, hipótesis que según Corominas y Pascual (1980) explicaría el género masculino en español. La lexicografía académica registra la voz malta en su acepción diatécnica a partir del 1899, mientras que los repertorios extraacadémicos la registran a partir de 1895 con la obra de Zerolo (1895), según datos del NTLLE (RAE, 2001). El equivalente malt, en cambio, no se registrará en ningún repertorio. Es un dato llamativo, puesto que la voz malt se documenta ya en la obra de Ballesteros de 1827: "Si el grano es simplemente contundido, es esta una preparación á que los fabricantes de Cervesa, y especialmente los ingleses, llaman el malt, el mismo que cuando es molido toma el nombre dreche ó hez de sebada” (1827, p. 22, las negritas son nuestras).

Este fragmento documenta el uso del anglicismo malt entre los cerveceros, los cuales manifestaban una inclinación hacia el recurso a préstamos de otras lenguas confirmada por la adopción del galicismo dreche 25 para designar los residuos de la elaboración de la cebada. Lo dicho nos permite considerar el manual objeto de nuestro estudio como la primera documentación de la forma malta, adaptada a los patrones fonéticos de la lengua española. La inclusión, en el texto, de la forma equivalente precedida de la conjunción copulativa $o$ puede leerse como prueba de una fuerte sensibilidad lingüística que lo conduce a proponer una solución al problema de adoptar un extranjerismo fonéticamente no compatible con la lengua española. La nota, además de definir esta palabra, informa al lector de que en la obra se hará uso de esta unidad léxica y del término maltage, del cual se indica que es el producto de la derivación morfológica del sustantivo anotado. El término francés, que no entrará en los repertorios lexicográficos de la época, se empleaba en la literatura científica decimonónica española en la forma adaptada maltaje antes de que se publicara este manual ${ }^{26}$. La influencia del francés es muy fuerte en el autor, tanto en el nivel lingüístico como nocional, puesto que en ambos manuales las referencias a ese contexto son numerosas. El elemento francés tan presente en las obras confirmaría la hipótesis según la cual Campano sería uno de tantos españoles que tuvieron que emigrar por la situación política del país durante el siglo XIX (Alvar Ezquerra, 2016, p. 169).

La nota 2 define la palabra lupulina, sustantivo que no penetra en la lexicografía académica y en los repertorios extraacadémicos se recoge a partir del diccionario de Domínguez ${ }^{27}$, cuya definición presenta cierta semejanza con la nota de Campano. El sustantivo lupulina es un derivado denominal, en el que el sufijo -ina manifiesta un valor semántico que, a partir del siglo XIX, irá difundiéndose en el dominio de la química (Pharies, 2002, s.v. -ina). Campano, gracias a su sensibilidad lingüística, percibe la necesidad de definir una 
palabra que, además de designar un concepto marcado diatécnicamente, presenta un patrón morfológico basado en un nuevo esquema semántico del sufijo -ina ${ }^{28}$.

En la nota 3, el autor asocia a la unidad léxica cubeta oval el equivalente francés reverdoir. Esta anotación no ha de leerse solo como el efecto de la comprobada influencia que el contexto francés ejerce en su obra, sino también como un intento de aportar una designación dotada de especificidad de campo mayor. La denominación española cubeta oval es un compuesto yuxtapuesto $\mathrm{N}+$ adj opaco semánticamente, al que es imposible para un lector no técnico relacionar su pertenencia al dominio del objeto de estudio. La escasez de especificidad de campo en el léxico de especialidad español en los siglos XVIII y en la primera mitad del XIX es una cuestión afrontada en los estudios de Corveddu (2017, 2018 y en prensa) y De Hoyos (2018), respectivamente sobre el léxico del curtido y adobo de cueros y del léxico económico. En las primeras etapas de los sectores científico-técnicos, para designar los conceptos se acude principalmente al léxico patrimonial de la lengua, predeterminado semánticamente a través de procesos basados en relaciones de analogía entre los conceptos $^{29}$. Sin embargo, el resultado de esta práctica era la acuñación de términos con escasa autonomía diatécnica, motivo por el cual en las tendencias neológicas sucesivas se percibe una propensión hacia nuevos mecanismos lexicogenéticos por medio de los cuales resolver este problema. La indicación del término francés, en nuestra opinión, ha de leerse en este contexto de búsqueda de una nueva identidad léxica. La nota 4 presenta la misma escasez de autonomía del dominio, lo cual es resultado de un fenómeno de trasvase léxico de un dominio de especialidad a otro, en este caso de la industria azucarera. El sustantivo raspador, así como el equivalente sinonímico propuesto rallo, no reciben un tratamiento lexicográfico que aborde este sentido diatécnico, se trata de otro ejemplo de unidad léxica perteneciente al fondo común de la lengua que se amplía semánticamente y se extiende a diferentes áreas del conocimiento. La nota 5, en cambio, define un préstamo del alemán del que no disponemos de los elementos suficientes como para reconstruir su origen. Su uso no se registra en ningún otro manual dedicado al tema y no se documenta en el CORDE, además, en los manuales de la época este mismo concepto no recibe denominación alguna. Es posible que Campano recurra a una voz probablemente marcada en diastratía para colmar este vacío. La nota 7 se sitúa en el capítulo dedicado a la historia del sector ${ }^{30}$, lo interesante de esta anotación es la presencia de una reflexión etimológica sobre el origen de los sustantivos cerveza y malt.

Terminamos el análisis del paratexto de este primer manual con una nota que trasluce el conocimiento por parte del autor de las dinámicas lingüísticas decimonónicas. Al comenzar su andadura, la química conduce hacia una reconfiguración del nivel léxico de numerosos dominios del conocimiento en los que se habían asentado formas tradicionales para denominar aquellos conceptos de los que ahora se han desvelado los secretos. El empleo de las voces tradicionales, junto a la nueva nomenclatura, era un fenómeno presente en diferentes obras publicadas en los siglos XVIII y XIX; a través de este recurso los científicos y los traductores intentaron limitar el problema de la comprensión por parte de quien no disponía de nociones de química (Garriga Escribano, 2004, pp. 189-192). En este caso, Campano indica el equivalente común de carbonato de cal $^{31}$, compuesto preposicional que se conforma a los patrones morfológicos propios de las nuevas concepciones de las ciencias y de las técnicas. La mayor especialización de este compuesto se puede considerar como la razón por la que se incluye en nota su variante tradicional, en otras palabras, a Campano le surge la misma preocupación que a los autores que se enfrentaron a la adopción de la nomenclatura química.

\subsection{El paratexto en el Manual del curtidor y del zurrador}

En su manual dedicado al arte del curtido de la piel, Lorenzo Campano propone un paratexto más amplio en comparación con la obra anterior, en el que destaca un diccionario de las sustancias vegetales y de los curtientes empleados durante el proceso. En la obra se enumeran 14 notas, 9 de las cuales presentan un contenido metalingüístico, como se puede observar a continuación (las cursivas son del texto): 
i. (nota lingüística a la palabra tan): adoptaremos esta palabra en el curso de nuestra obra (1869b, p. 18).

ii. (nota lingüística a la palabra Tenería): lo mismo que curtiduria (1869b, p. 20).

iii. (nota lingüística a la palabra Cueros ó pieles verdes): En vez de la palabra piel úsase por lo comun la de cuero en el comercio,

llamando cueros verdes á las pieles frescas, cueros curtidos á los que están fabricados ya, etc. (1869b, p. 22).

iv. (nota lingüística a la palabra Changrin): nombre dado por los franceses á una clase de cuero granoso (1869b, p. 25).

v. (nota lingüística a la palabra Mano de calandria): asi se llama la operacion del lustre (1869b, p. 163).

vi. (nota lingüística a la palabra Cueros cogidos en costra): cuero en costra es el que aun no está sobado (1869b, p. 169).

vii. (nota lingüística a la palabra Trabajo de palmeta): palmeta es el nombre del instrumento con que se verifica la operacion.

Llámase de este modo porque cubre la palma de la mano, con la cual se trabaja. Impropriamente ha sido llamada pamela (1869b,

p. 172).

viii. (nota lingüística a la palabra Potasa): los franceses llaman dégras al agua de potasa despues de haber servido para desgrasar

las pieles de gamuza (1869b, p. 183).

ix. (nota lingüística a la palabra Degras): Adoptamos la palabra por brevedad (1869b, p. 185).

Desde una primera lectura, se percibe que la influencia de la lengua francesa y en general de su contexto es aún más profunda que en el manual dedicado a la cerveza. La nota 1 informa sobre la decisión de emplear a lo largo de la obra la palabra francesa tan (corteza de encina), uno de los más antiguos curtientes vegetales empleados por el ser humano. El concepto de corteza de encina en cuanto curtiente no dispone de una palabra dedicada a ello en la lengua española, de hecho, en los manuales dieciochescos y decimonónicos se registra el compuesto corteza de encina o por ampliación semántica el mismo sustantivo encina. Viene así confirmándose la escasez generalizada de especificidad de campo en los dominios relacionados con las artes y los oficios, lo cual lleva a situaciones de polisemia que reducen la precisión que se espera en un lenguaje diatécnico. Campano no fue el primero en darse cuenta de esta falta en el léxico español, puesto que la palabra francesa tan había llamado la atención del padre Terreros y Pando, el cual adoptará el galicismo en su adaptación de la obra francesa del abad Pluche, además de registrarla en su repertorio lexicográfico póstumo. A la influencia francesa se debe incluso la nota 2, donde el autor informa sobre el sinónimo de la palabra tenería. Este último es un galicismo, deriva de la palabra tannerie (derivado de tan), resulta ser bien arraigado en el tejido léxico español y se documenta a partir del siglo XII (Corominas y Pascual, 1980, p. 463). Un dato significativo es que en los manuales de la época se recurre con más frecuencia el galicismo tenería (Corveddu, 2017), tanto en los textos dieciochescos como en los decimonónicos. La inclusión de esta nota puede leerse como un recurso que el autor ofrece al lector para facilitar la comprensión del texto, evidentemente percibiendo el sustantivo curtiduría como variante más difundida en contextos de uso no diatécnicos.

La observación que Campano ofrece por medio de la nota 3 documenta una situación de solapamiento semántico entre los sustantivos piel y cuero, ambos empleados para designar la piel del animal en cuanto materia prima. La nota localiza el solapamiento fuera del contexto comunicativo diatécnico, y especifica que se trata de una costumbre típica del comercio. De hecho, en los manuales del tiempo, las dos unidades léxicas se conforman a los significados con los que se han asentado en el tejido léxico español, es decir, piel en cuanto materia prima y cuero en cuanto denominación de la piel curtida sin el pelo, es decir, el producto acabado 32. La sensibilidad lingüística del autor le permite percibir esta anomalía con respecto al uso documentado en la literatura, por eso decide informar al lector, y se limita a presentar la cuestión sin añadir indicaciones prescriptivas.

La palabra Changrin (chagren según la ortografía francesa) es un galicismo que denomina una piel (generalmente de caballo o asno) curtida y adobada para resaltar la granulosidad ${ }^{33}$. El uso de este préstamo se ve confirmado en García López (1892, p. 223), si bien se presenta como equivalente de la forma española piel de zapa. Para reconstruir los motivos que condujeron a Campano a favorecer el uso del galicismo frente al equivalente español, hemos acudido a la lexicografía, gracias a la cual se ha trazado un escenario en el que la polisemia se configura como el problema principal:

Zapa: Lija, por la piel del pescado. Cualquier género de piel preparada á su imitación (RAE, 1852, s.v. Zapa) (NTLLE, 2001). 
Lija: Nombre dado en los artes á la piel áspera del dicho y de otros varios, que sirve para alisar la madera y otros usos (RAE, 1852, s.v. Lija) (NTLLE, 2001).

Desde una primera lectura, los repertorios académicos transparentan un déficit de exclusividad terminológica, lo cual reduce este concepto a la ampliación semántica de una palabra perteneciente al fondo léxico de la lengua. La polisemia no es la única consecuencia a la que lleva la lexicogénesis de esta palabra, puesto que este mismo concepto se designa también por medio de la palabra lija. Analizando la evolución del tratamiento lexicográfico de este concepto, se aprecia la introducción de la entrada chagrén y de su variante ortográfica chagrin (RAE, 1927, extraído del NTLLE, 2001), prueba de la difusión del galicismo. La presente anotación se enmarca en la propensión del autor hacia la adopción de una lexía que ofrezca el mayor grado de precisión, en este caso, una forma léxica procedente de otra lengua que se muestra suficientemente asentada en el discurso técnico, para que no dé lugar a malas interpretaciones. En esta misma línea se insertan las notas 8 y 9, dedicadas al galicismo degras que designa la mezcla de materias grasas y residuos procedentes del agamuzado de las pieles, mezclados con otras materias grasas animales. La introducción de un préstamo, en este caso, se debe a la falta de un equivalente en lengua española, motivo por el cual a esta misma voz recurren en otros manuales sobre el curtido y adobo del cuero ${ }^{34}$.

La definición de las palabras que podrían plantear problemas de comprensión se repite con frecuencia en las notas del autor, por esta razón en el presente estudio no consideramos las notas terminológicas como un simple contenido, sino como una herramienta que el autor ofrece en respuesta a la opacidad semántica o a la naturaleza polisémica de algunas unidades. Enfocamos la atención en las notas 5 y 6 , donde los términos a los que se asocian se caracterizan por tipicidad formal, de modo que se consideran una estructura composicional estándar de la lengua española: $\mathrm{N}+$ prep $+\mathrm{N}$. Para desentrañar las razones que subyacen a la inclusión de estas reflexiones hay que reconstruir la configuración semántica de estos compuestos. En cuanto a mano de calandria, designa un proceso de elaboración con el que se da lustre al cuero curtido. El primer elemento de interés es su estructura morfológica, la cual se ajusta a la nueva tendencia lexicogenética que producirá un cambio profundo en las dinámicas léxicas del sector (Corveddu, 2017). A partir del siglo XIX, la entrada de la química y los avances de la mecánica generarán una necesidad denominativa que resultará en una producción neológica abrumadora. Tras el incremento del volumen léxico, desde el punto de vista terminológico se impone una nueva tendencia en favor del empleo del mecanismo de la composición ${ }^{35}$. Así configurados, los neologismos dotan el léxico de una nueva independencia semántica, prueba evidente de un asentamiento epistemológico de la disciplina; sin embargo, aumentan las situaciones de opacidad debido a uno de los lexemas que forma parte del compuesto. En mano de calandria se localiza en el elemento modificador calandria, denominación de una máquina recién introducida en el sector en sustitución del gravoso trabajo manual $^{36}$. La interpretación habría sido imposible para quien no hubiera poseído conocimientos específicos del sector, mientras que para los especialistas resulta inmediata. El carácter novedoso de este concepto y la ausencia de un tratamiento lexicográfico propio para esta acepción las consideramos razones por las que Campano decidió incorporar la indicación en el manual.

Lo dicho abarca incluso el compuesto cuero en costra, unidad léxica que además de no penetrar en la lexicografía, en los contextos de uso manifiesta una naturaleza polisémica; junto a la acepción de cuero recién curtido que encontramos en Campano ${ }^{37}$, el sustantivo se emplea como denominación de un producto semielaborado diferente ${ }^{38}$. En una situación en la que la unidad léxica no ha todavía llegado a un asentamiento semántico, desarrolla una polisemia interna al mismo dominio del conocimiento, el autor actúa aclarando la acepción con la que el término se adopta en el texto. A la actitud lingüística del autor se asocia, en este caso, el conocimiento del sector, prueba de que sus obras se basan en una sólida actividad de documentación.

Terminamos el análisis de las notas con la reflexión metalingüística que el autor pone a la construcción trabajo de palmeta. Se ajusta a los patrones morfológicos de la época, pues presenta una estructura 
preposicional que da origen a una denominación donde la transparencia semántica para el público de especialistas va en detrimento del lector común. Esta opacidad, la misma encontrada en la construcción mano de calandria, se debe a la tecnicidad del elemento modificador palmeta. Además de designar un instrumento propio de la elaboración de los cueros curtidos, al que se acudía para granear la superficie del material o bien para suavizarlo, se trata de un calco léxico de la palabra francesa paumelle ${ }^{39}$. El uso del término palmeta se documenta incluso en la obra de García López (1892), el cual ofrece una descripción etimológica ${ }^{40}$. Este aspecto es muy significativo si consideramos que en su manual el paratexto es muy limitado, así como cualquier explicación que escape al objetivo referencial del texto. La definición no se limita a solucionar el problema de la opacidad, sino también la difusión de una variante ortográfica, pamela, cuya difusión parece resultar de una adaptación ortográfica del francés (cuyo uso no se asentará en el discurso oficial).

A diferencia del manual dedicado a la cerveza, forma parte del paratexto una sección en la que Campano incluye un diccionario de los vegetales y de las materias curtientes que define como las más conocidas en la tenería. Estamos frente a un glosario de 128 unidades, cada una de las cuales presenta una definición enciclopédica, que en muchas ocasiones incluye eventuales equivalentes sinonímicos seguidos de la conjunción copulativa ó. De interés para nuestro estudio son las dos notas con la que el autor enriquece este apartado:

i. (nota a la palabra millepertuis): nombre francés de la planta (1869b, p. 264).

ii. (nota a la palabra zumaque): en el comercio se da también el nombre de zumaque al polvo que se obtiene del tallo y hojas de la planta del mismo nombre [...] (1869b, p. 278).

La nota 1 confirma la influencia que el contexto francés ejerce en el estilo del autor, al que hemos observado recurrir en varias ocasiones a los galicismos para aumentar la precisión de las denominaciones. La nota sucesiva, en cambio, informa al lector sobre un uso polisémico del sustantivo zumaque, cuya primera acepción es el nombre de una planta conocida en particular para la propiedad astringente de su extracto. Se trata de una unidad bien asentada en el tejido léxico de la lengua española, su empleo entre los curtidores se señala ya en Covarrubias (1611) ${ }^{41}$ y sigue presentándose a lo largo de toda la tradición lexicográfica académica y extraacadémica.

\section{Conclusiones}

Lorenzo Campano sigue siendo un personaje desconocido del panorama cultural decimonónico, sin embargo, sus reflexiones nos ayudan a delinear su figura de investigador riguroso y sensible a las dinámicas léxicas. La muestra de sus notas confirma el interés para los ámbitos científico-técnicos, en particular para el léxico de las artes y oficios. Su interés se refleja en su Diccionario General Abreviado, tanto en el volumen de estas voces como en la articulación del sistema de marcas diatécnicas que encontramos en la microestructura de este repertorio (Alvar Ezquerra, 2016, pp. 175-179). Al interés por áreas del conocimiento del que tradicionalmente se ha dedicado poca atención en España, se une una concienciación lingüística que lleva a este autor poliédrico a enriquecer sus obras con informaciones paralelas, y solucionar algunos de los problemas que el desarrollo léxico de la época planteaba.

Para el historiador de la lengua, las anotaciones de Campano representan un recurso fundamental para apreciar algunos de los cambios que el léxico decimonónico, sobre todo en los ámbitos diatécnicos, estaba experimentando. En primer lugar, las reflexiones de Campano ponen en evidencia una falta de exclusividad terminológica en ambos sectores. El recurrir a galicismos se ha interpretado como una respuesta a este fenómeno, que adquiere una relevancia notable en una época de transición para las artes y oficios tradicionales. Las anotaciones del autor se convierten en testimonios de este contexto, gracias a los cuales es posible apreciar las implicaciones de las dinámicas lingüísticas en la realización de un manual técnico. Las reflexiones con las que el autor enriquece sus obras muestran también que los avances diatécnicos no 
tuvieron como consecuencia solo la introducción de neologismos, sino también un cambio en las tendencias de empleo de los mecanismos lexicogenéticos. En el manual dedicado al curtido de la piel se confirma un incremento en la adopción de la composición, mecanismo cuya productividad permite hacer frente a la exigencia de denominar los nuevos conceptos que, en pocas décadas, reconfigurarán la estructura conceptual de este dominio del conocimiento ${ }^{42}$.

\section{Bibliografía}

Alvar Ezquerra, M. (2016). El Diccionario general abreviado de la lengua castellana de Lorenzo Campano (1876). En A. López Serena (Ed.), El español a través del tiempo. Estudios ofrecidos a Rafael Cano Aguilar (pp. 169-186). Sevilla: Universidad de Sevilla.

Analyse et Traitement Informatique de la Langue Française (ATILF). (1994). Trésor de la langue Française informatisé. [Versión en línea]. Recuperado de http://www.atilf.fr/tlfi

Ballesteros, J. M. (1827). Opúsculo sobre la cerveza: método de elaborarla: Sus virtudes como medicamento y como bebida ordinar. Madrid: Imprenta de Norberto Llorenci.

Caballero Escribano, C. (2013). Historia de los curtidos de las pieles. Alicante: Editorial Club Universitario.

Campano, L. (1868). Biografía del libertador Simón Bolivar, o la independencia de la América del sud. París: Librería de Rosa y Bouret.

Campano, L. (1869a). Manual del cervecero y del fabricante de bebidas gaseosas y fermentadas. Obra extractada de los mejores métodos modernos. París: Librería de Rosa y Bouret.

Campano, L. (1869b). Manual del curtidor y del zurrador. París: Librería de Rosa y Bouret.

Campano, L. (1869c). Viajes a las cinco partes del mundo. Relaciones, aventuras, exploraciones y descubrimientos, extractados de las mejores obras de los célebres viajeros. París: Librería de Rosa y Bouret.

Campano, L. (1876). Diccionario general abreviado de la lengua castellana, el más completo de los publicados hasta el dia, que abraza los términos literarios y los del lenguaje usual en su sentido propio y figurado, las voces usadas en las ciencias, artes y oficios y los nombres propios de historia, geografía, biografia y mitologia, ordenado por Lorenzo Campano. Conforme a los diccionarios de la Academia Española, Salvá, Grégoire, Dominguez, etc. París: Librería de Garnier Hermanos.

Campano, L. (1881). Abecedario ilustrado: Libro primero de lectura escrito con un método especial y dedicado a los niños. Paris: Charles Bouret.

Campano, L. (1864). Compendio de Historia de España, consagrado a los niños y punto en verso. Madrid: D. Zacarias Soler.

Corominas, J. y Pascual J. A. (1980). Diccionario crítico etimológico castellano e hispánico. Madrid: Gredos.

Corveddu, M. S. (2017). L'arte della pelle e del cuoio. Evoluzione del lessico specialistico spagnolo tra i secoli XVIII e XIX. (Tesis doctoral). Università Cattolica del Sacro Cuore.

Corveddu, M. S. (2018). El léxico técnico y los problemas de traducir un arte en la España ilustrada. Les pelletteries et apprêt de cuir de Noël-Antoine Pluche, análisis léxico de la traducción de Esteban de Terreros y Pando. Anuario de Letras. Lingüistica y Filología, 6(1), 35-73.

Corveddu, M. S. (En prensa). Análisis diacrónico de los mecanismos de creación neológica en un léxico técnico: el curtido y adobo de cueros en los siglos XVIII y XIX. PeterLang.

Covarrubias, S. (1611). Tesoro de la Lengua Castellana o Española. Madrid: Luís Sánchez.

De Hoyos, J. (2018). Léxico económico en la lengua española de principios del XIX. El Epitome de Jean-Baptiste Say. San Millán de la Cogolla: Cilelengua.

Fernández Sevilla, J. (1974). Problemas de lexicografía actual. Bogotá: Instituto Caro y Cuervo.

García Barber, X. (2014). La cerveza en España: orígenes e implantación de la industria cervecera. Madrid: LID Editorial Empresarial. 
Mario Salvatore Corveddu. La Sensibilidad lingüística de Lorenzo Campano en su producción científi...

García Hurtado, M. (1999). La traducción en España, 1750-1808: cuantificación y lenguas en contacto. En F. Lafarga (Ed.), La traducción en España (1750-1830). Lengua, literatura, cultura (pp. 35-43). Lérida: Universitat de Lleida.

García López, M. (1892). Fabricación de Curtidos. Tratado de la preparación de las pieles y obtención de cueros, vaquetas, becerros, tafiletes, sapas, cordobán, pergamino, etc., con los sistemas de coloración y tinte de los mismos seguido del arte de la peletería y manguitería según los procedimientos más modernos. Madrid: Hijos de Cuesta Editores.

Garriga Escribano, C. (2001). Notas sobre el vocabulario de la química orgánica en español. Liebig y la divulgación de los derivados en -ina. En M. Bargalló Escrivá, E. Forgas Berdet, C. Garriga Escribano, A. Rubio y J. Schnitzer (Coords), Las lenguas de especialidad y su didáctica: actas del simposio Hispano-Austriaco (pp. 169-180). Tarragona: Universitat Rovira i Virgili.

Garriga Escribano, C. (2003). Aspectos de la adaptación de la nueva nomenclatura química al español (siglos XVIII y XIX).Panace@: Revista de Medicina, Lenguajey Traducción, 4(11),36-49.

Garriga Escribano, C. (2004). Lengua y ciencia en español: reflexiones lingüísticas de los científicos en los siglos XVIII y XIX. En M. T. Cabré (Ed.), Objetividad científica y lenguaje (pp. 183-193). Barcelona: IULA-UPF.

Garriga Escribano, C. (2015). Historia del léxico y lexicografía especializada: el "Diccionario industrial; artes y oficios de Europa y América" (1888-1891) de Camps y Armet como fuente. Etudes romanes de Brno, (1), 61-84.

Genette, G. (1987). Seuils. París: Éditions du Seuil.

Gutiérrez Rodilla, B. (2013). Sobre la formación de palabras y el léxico científico: algunas nociones generales y varias preguntas en el aire. En P. Pujol (Ed.), Formación de palabras y diacronia (pp. 69-78). La Coruña: Universidad de La Coruña.

Lafarga, F. (Ed.). (2004). Historia de la traducción en España. Salamanca: Ambos Mundos.

Martínez, L. (1848). Manual para la fabricación de vinos y modo de remediar sus alteraciones. Madrid: Imprenta de Manuel Álvarez.

Miguelez, C. (1805). Arte de Curtir ó Instruccion General de Curtidos dado á la luz por Don Cayetano Miguelez, vecino de esta corte. Madrid: Imprenta Real.

Muñoz Armijo, L. (2013). Morfología léxica del sufijo -ina: análisis de los derivados en la lexicografía académica española del siglo XVIII. En A. Kuzmanović, J. Filipović, J. Stojanović y J. Rajić (Eds), Estudios hispánicos en el siglo XXI (pp. 273-289). Universidad de Belgrado.

Muñoz Armijo, L. (2014). Procesos de lexicalización en el patrón evaluativo de los sustantivos en -ina. En B. Camus Bergareche (Ed.), Morfología y diccionarios (pp. 105-122). España: Universidade da Coruña.

Muñoz Armijo, L. (2015). De la resina a la queratina: la extensión semántica del patrón derivativo de las sustancias en -ina y su difusión en el español moderno. En M. L Arnal Purroy, R. M. Castañer Martín, J. M. Enguita Utrilla, V. Lagüéns Gracia y M. A. Martín Zorraquino (Coords.), Actas del X Congreso Internacional de Historia de la Lengua Española (pp. 1241-1260). Zaragoza: Institución Fernando el Católico.

Muñoz Armijo, L. (2016). Evolución morfológica y semántica del sufijo -ina: notas sobre la recepción de sus derivados en la lexicografía académica española de los siglos XIX y XX. En R. Cotelo García (Ed.), Entre dos coordenadas: las perspectiva diacrónica y diatópica en los estudios léxicos del español (pp. 277-296). Madrid: Cilengua.

Pharies, D. (2002). Diccionario etimológico de los sufjos españoles y de otros elementos finales. Madrid: Gredos.

Pinilla Martínez, J. y Lepinette, B. (2009). La aportación propia del traductor al texto científico-técnico traducido o el afán de divulgación de un saber foráneo. A propósito del paratexto en una traducción al español de H. L. Duhamel du Monceau (1700-1782). Cuadernos del Instituto de Historia de la Lengua, (3), 109-126.

Ramírez Luengo, J. (2017). El léxico de un culto centroamericano en los inicios del siglo XIX: notas sobre la memoria del estado político y eclesiástico de la capitanía general de Guatemala (1821), de J. M. Méndez. Philologica Canariensia, (23), 63-78.

Real Academia Española (RAE). (2001). Nuevo tesoro lexicográfico de la lengua española (NTLLE). Recuperado de ht tps://www.rae.es/obras-academicas/diccionarios/nuevo-tesoro-lexicografico-0 
Ronquillo Oriol, J. (1853). Diccionario de materia mercantil, industrial y agricola. Barcelona: Imprenta de Augustin Gaspar.

Roqué y Pagani, P. (1851). Curso de Quimica Industrial. Madrid: Imprenta del Porvenir.

Ruiz Pérez, J. M. (M. Sanz, ed.). (1845). Tratado teórico y práctico de la fermentación espirituosa o alcohólica, fundado en experiencias hechas con diferentes frutos y sustancias sacarinas, aplicable al arte de fabricar vinos y aguardientes con mostos naturales y artificiales. Granada: Imprenta y Librería de Don Manuel Sanz.

Sánchez Martín, J. F. (2018). Herencias e innovaciones en el léxico matemático español peninsular del siglo XIX. Onomázein, (39), 151-168.

Santana, O., Pérez, J. R., Rodríguez G. y Carreras F. J. (2004). Relaciones morfoléxicas sufjales para el procesamiento del lenguaje natural. Madrid: Mileto.

Serrano, E. (2012). The Spectacle de la Nature in Eighteenth-Century Spain: From French Households to Spanish Workshops. Annals of Science, 69(2), 257-282.

Terreros y Pando, E. (1754). Las Tenerias y adovo de cueros. En Espectaculo de la naturaleza, o Conversaciones a cerca de las particularidades de la historia natural... escrito en el idioma francès por el Abad M. Pluche; $y$ traducido al castellano por el P. Estevan de Terreros y Pando... (pp. 186-209). Madrid: Oficina de Gabriel Ramirez.

Thomson, R. (1981). Tanning. Man’s First Manufacturing Process? Transactions of Newcomen Society, 53(1), 139-156.

Torras y Ribé, J. M. (1994). La industria del curtido en Cataluña: del trabajo manual al uso de la energía eléctrica. En J. Nadal (Ed.), La cara oculta de la industrialización española. La modernización de los sectores no líderes (pp. 295-321). Madrid: Alianza.

Wurtz, A. (1878). Dictionnaire de Chimie pure et appliquée. París: Librairie Hachette et Cie.

\section{Notas}

1 Este aspecto ha sido destacado por Garriga Escribano en varios estudios, entre los cuales destaca el de 2003 (pp. 36-49) y el de 2015 (p. 62). A estos cabe añadir el estudio clásico de Fernández Sevilla (1974, p. 141).

2 Sobre el léxico de la ciencia y de la técnica en los siglos XVIII, XIX y XX es de suma importancia la actividad investigadora del grupo NEOLCYT, dirigido por el profesor Cecilio Garriga Escribano. El grupo ha llevado a cabo estudios sobre el léxico del ferrocarril, de la enología, de la química y de la física entre otros: http://dfe.uab.cat/neolcyt/index.php? option $=$ com_content\&view $=$ frontpage\&Itemid $=1 \&$ lang=es

Además, destacan los estudios de Sánchez Martín sobre la dinámica léxica en varias ciencias y en particular en las matemáticas, entre otros (léase 2018, pp. 151-168). En el área hispanoamericana de suma importancia son los estudios de Ramírez Luengo, entre los cuales destaca el de 2017 (pp. 63-78).

3 Ahora bien, para comprender la naturaleza de la dinámica léxica dieciochesca ha de considerarse que la química todavía estaba la comenzando su andadura con la publicación en 1787 de una obra colectiva, titulada Méthode de nomenclature chimique, traducida al español en ese mismo año por Gutiérrez Bueno; además, la concepción de técnica se proyectaba en las artes y oficios que aún estaban lejos de considerarse industria.

4 Abecedario ilustrado: Libro primero de lectura escrito con un método especial y dedicado a los niños, Paris, Charles Bouret, 1881; Compendio de Historia de España, consagrado a los niños y punto en verso, Madrid, D. Zacarías Soler, 1864.

5 Manual del cervecero y del fabricante de bebidas gaseosas y fermentadas. Obra extractada de los mejores métodos modernos , 1869a, París, Librería de Rosa y Bouret; Manual del curtidor y del zurrador, 1869b, París, Librería de Rosa y Bouret.

6 Biografia del libertador Simón Bolivar, o la independencia de la América del sud (1868) o Viajes a las cinco partes del mundo. Relaciones, aventuras, exploraciones y descubrimientos, extractados de las mejores obras de los célebres viajeros (1869c).

7 Diccionario general abreviado de la lengua castellana, el más completo de los publicados hasta el día, que abraza los términos literarios y los del lenguaje usual en su sentido propio y figurado, las voces usadas en las ciencias, artes y oficios y los nombres propios de historia, geografia, biografia y mitologia, ordenado por Lorenzo Campano. Conforme a los diccionarios de la Academia Española, Salvá, Grégoire, Dominguez, etc. , 1876, París, Librería de Garnier Hermanos.

8 Sobre la obra léanse Alvar Ezquerra (2016, pp. 169-186).

9 Por un análisis detallado de la historia editorial de la cerveza y en general para profundizar el panorama de la industria cervecera en España léase García Barber (2014). 
10 "Si bien había algunas obras que por incidencia hablasen sobre la cerveza, no existía una que tratase exclusivamente de la misma... quedo satisfecho si logro satisfacer los deseos de tantos curiosos que echaban de menos noticias sobre una bebida, que haciéndose de día en día más general, les era cuasi misteriosa su composición” (Ballesteros, 1827, pp. IV-V).

11 Capítulo 2: "Primeras substancias empleadas en la fabricacion de la cerveza" (1869a, pp. 15-32).

12 Respectivamente en los capítulos 3 "Fabricacion de la cerveza” (1869a, pp. 33-68) y 4 "Del braceo" (1869a, pp. 71-99).

13 Capítulo 9: "De los diferentes métodos de fabricación” (1869a, pp. 183-200).

14 Capítulo 7 "Noticias importantes relativas á algunos puntos de la fabricacion" (1869a, pp. 143-167) y 12 "Noticias varias" (1869a, pp. 233-241).

15 Capítulo 6: "Cuidados que se deben tener con las cervezas jóvenes mientras están en la bodega” (1869a, pp. 131-136).

16 Capítulo 8: "De los instrumentos necesarios al fabricante de cerveza” (1869a, pp. 169-179).

17 Capítulo 10: "Del local de una fábrica de cerveza” (1869a, pp. 203-224) y capítulo 11: “Bodegas para cervezas jóvenes y cervezas de conserva".

18 Sobre el tema léanse Torras y Ribé (1994, pp. 295-321) y Caballero Escribano (2013).

19 Por una reconstrucción del contexto consúltense los estudios de García Hurtado (1999) y Lafarga (2004).

20 Sobre la labor de Terreros y Pando para adaptar la obra de Pluche al español consúltese el pormenorizado estudio de Serrano (2012, pp. 257-282).

21 Sobre las reflexiones lingüísticas de los traductores de textos químicos cabe mencionar los estudios de Garriga Escribano (2003 y 2004).

22 La herramienta que se ha privilegiado para la consulta de la lexicografía diacrónica es el Nuevo Tesoro Lexicográfico de la Lengua Española (NTLLE) (RAE, 2001), a partir del cual se han consultado los diccionarios monolingües dieciochescos y decimonónicos mencionados en el presente estudio, a excepción del Covarrubias (1611).

23 Sobre la cervecería hemos consultado los siguientes manuales: Opúsculo sobre la cerveza: método de elaborarla: Sus virtudes como medicamento y como bebida ordinar (Ballesteros, 1827) y el Manual para la fabricación de vinos y modo de remediar sus alteraciones (Martínez, 1848). Sobre el curtido y adobo de cueros, en cambio, hemos consultado: Arte de Curtir ó Instruccion General de Curtidos dado á la luz por Don Cayetano Miguelez, vecino de esta corte (Miguelez, 1805) y Fabricación de Curtidos. Tratado de la preparación de las pieles y obtención de cueros, vaquetas, becerros, tafiletes, sapas, cordobán, pergamino, etc., con los sistemas de coloración y tinte de los mismos seguido del arte de la peletería y manguitería según los procedimientos más modernos (García López, 1892).

24 "tout cepar quoi un texte se fait libre et propose comme tel à sus lecteurs, et plus généralement au public" (Genette, 1987, p. 7).

25 (Drêche): Résidu d'orge cuite qui reste dans la cuve après la cuisson de la bière et le soutirage du moût (ATILF, 1994, s.v. drêche), https://www.cnrtl.fr/definition/dreche

26 La forma maltaje se registra ya en el Curso de quimica industrial (1851, p. 157) de Pedro Roqué y Pagani.

27 (Lupulina): nombre que se dio a cierto polvo amarillento dorado, resinforme, aromático y amargo, que se encuentra en la época de la madurez en la base de la superficie esterna de las brácteas, donde estan formadas las pinas del lúpulo, así como en el eje que las sostiene (Domínguez, 1853, s.v. Lupulina) (NTLLE, 2001).

28 El origen del sufijo -ina se remonta al latín, en este estadio clásico se adjunta a bases léxicas nominales y verbales para la creación de sustantivos. En el siglo XIII se documentan los primeros usos internos a la lengua española, las formaciones anteriores se acuñan imitando al modelo latino. El estudio de Santana, Pérez, Rodríguez y Carreras (2004, p. 39) señala el ingreso en el mundo de la química a partir del siglo XIX. Sobre la partícula -ina consúltense Muñoz Armijo (2013, 2014, 2015 y 2016); sobre el valor del sufijo en el dominio de la química, Garriga Escribano (2001).

29 Esta misma afirmación sobre el lenguaje de la ciencia la encontramos en Gutiérrez Rodilla (2013, pp. 69-78).

30 Cabe destacar que, en algunos manuales dedicados a las artes y oficios, se evidencia la costumbre de incluir un capítulo dedicado a los métodos tradicionales. Esta costumbre se ha evidenciado en los manuales que se han consultado para el presente estudio.

31 Del Diccionario de materia mercantil (Ronquillo Oriol, 1853, p. 269) aprendemos que la voz blanco de España es la denominación que fuera de la comunicación especializada recibe el carbonato de cal.

32 Esta afirmación se basa en el análisis del léxico en los manuales de Miguelez (1805) y García López (1892), resultado de un análisis conducido en un trabajo más amplio de tesis doctoral en la que se ha reconstruido y analizado el léxico histórico del curtido y adobo de las pieles.

33 Para las reflexiones conducidas sobre las palabras francesas se ha empleado el Trésor de la langue Française informatisé (ATILF, 1994): http://www.atilf.fr/tlfi

34 Un ejemplo es el manual de García López (1892, p. 163).

35 Esta nueva tendencia se describe en el estudio de Corveddu (2017), el cual analiza los cambios de tendencias morfológicas en el léxico del curtido y adobo de cueros.

36 La inmovilidad diatécnica es una de las características de este sector, el cual comienza su andadura hacia la modernidad solo a partir de la segunda mitad del siglo XIX. La mecanización de las prácticas manuales es uno de los cambios más representativos de este cambio hacia la modernidad. 
Revista de Filología y Lingüística de la Universidad de Costa Rica, 2021, vol. 47, núm. 2, e46943, ...

37 Esta misma acepción se encuentra incluso en el siglo XVIII en el texto de Terreros (1786, p. 204) (NTLLE, 2001).

38 En el manual de García López (1892, p. 117) encontramos la siguiente descripción de los cueros en costra: "Las costras proceden de los cueros de buey aserrados en el sentido de su grueso, formando dos hojas; se llama vaca, la parte ú hoja que conserva la flor [...]".

39 (Paumelle): Outil de bois qui sert à donner aux peaux la souplesse et le grain. Tirer à la paumelle. À cet effet, on rabat un quartier de la peau fleur contre fleur, on avance la paumelle, puis on la retire fortement (Wurtz, 1878, p. 189, las cursivas son nuestras), http://www.atilf.fr/tlfi

40 Útil de varios tamaños llamado así porque cubre la palma de la mano que la maneja durante el trabajo, es cuadrangular, plana por el dorso, en donde tiene un asa ó abrazadera de cuero para pasar la mano, y arqueada, con acanalado más o menos grueso, en la cara útil y transversalmente sobre la anchura (García López, 1892, p. 152).

41 (Cvmaque): cierta yerba de que usan los çurradores para curtir los cueros con el agua, o çumo della [...] (Covarruvias, 1611, p. 289).

42 Los cambios de tendencias lexicogenéticas en el ámbito del curtido y adobo de cueros han sido estudiados en Corveddu (en prensa). 